\title{
Método Clínico: Método Clínico?
}

\author{
Fernando Aguiar ${ }^{1}$ \\ Universidade Federal de Santa Catarina
}

\begin{abstract}
Resumo
Este artigo retoma a noção de método clínico, situando-a no contexto da psicologia clínica francesa. Por sua vez, a psicologia clínica francesa não pode ser examinada historicamente senão em sua relação com a psicanálise. A estreita conjunção entre psicologia clínica e psicanálise, formulada na França nos termos de uma "unidade da psicologia", inclui a noção de método clínico. Tendo assim uma derivação eminentemente psicanalítica, essa noção é hoje mais do que nunca contestada, ou mesmo distorcida pelo ecletismo metodológico e pela prevalência, na psicologia clínica mundial, de procedimentos experimentais. Palavras-chave: Método clínico; psicologia clínica; psicanálise.
\end{abstract}

\section{Clinical Method: Clinical Method?}

\begin{abstract}
This article resumes the notion of a clinical method in the context of French Clinical Psychology. Any historical examination of this context however includes its relationship with Psychoanalysis. The relationship between Clinical Psychology and Psychoanalysis, formulated in France in terms of a "Unit of Psychology", includes the notion of clinical method. Thus, having derived immanently from Psychoanalysis, the notion of clinical method has been contested and even distorted more than ever by methodological eclecticism and by the prevalence, in the worldwide Clinical Psychology, of experimental procedures. Keywords: Clinical method; clinical psychology; psychoanalysis.
\end{abstract}

A França e os Estados Unidos reivindicam a primazia de ser o berço da psicologia clínica. Em que pese o chauvinismo implícito na disputa, é certo que se pode fazer pelo menos duas afirmações sobre a questão. Primeiro, especificada pelo chamado "método clínico", esta modalidade de investigação dos processos anímicos constitui-se, de maneira emblemática no país europeu, em um dos pólos da dualidade metodológica própria à psicologia praticada em todos os quadrantes - sendo o outro o método experimental. Segundo, em nenhum outro lugar, o nascimento e a constituição da psicologia clínica resultou de uma associação tão estreita e particular com a psicanálise como aquela ocorrida na França.

A psicanálise teria ali servido à psicologia como caução teórica e como exemplo, mesmo como modelo de prática. Em troca, a psicologia teria servido de veículo para a difusão da psicanálise em um país que, por um largo período de tempo, foi indiferente ou reticente ao freudismo (Anzieu, 1979, Assoun, 1981). De tal forma

1 Endereço para correspondência: Departamento de Psicologia, CFH, UFSC, Campus Universitário, Trindade, Florianópolis, SC. Fone: (48) 3319904, Fax: (48) 3319984.E-mail: fabs@cfh.ufsc.br

2 Cf., a respeito, Aguiar, 2000. que não se pode falar em método clínico sem considerar as implicações políticas (política na teoria), históricas e metodológicas de um evento que ainda hoje continua a produzir seus efeitos, e não apenas na França.

Neste artigo, depois de apresentar brevemente essas questões $^{2}$, consideramos a seguir a tendência, sempre em curso desde os anos 1960, que reivindica entre outras coisas o ecletismo em psicoterapia, amplia de procedimentos nítida e convencionalmente experimentais na clínica psicológica, e, no caso francês, denuncia supostos malefícios da conjunção entre a psicanálise e a psicologia clínica. Apoiando-se em "raízes" tão diversas como o movimento humanitário e o movimento de higiene mental do século XVIII, a própria psicologia geral e experimental e a psicologia diferencial, a philosophie de la vie (Bergson, entre outros) e a fenomenologia, Freud e Janet (Huber, 1993), essa tendência coloca em questão a existência mesma de um método clínico em psicologia clínica - revelando-se hegemônica, parece-nos, deve renunciar ao epíteto e à noção. Porque em sua radicalidade histórico-conceitual, o método clínico pressupõe duas dimensões paradigmáticas e próprias da clínica psicanalítica: a singularidade do sujeito (que, na cena francesa, foi um principio fundador da psicologia clínica) e, conseqüentemente, a idéia de uma contemporaneidade entre pesquisa e tratamento. 


\section{Da Clínica Médica à Clínica Psicológica}

$\mathrm{Na}$ sua origem, o termo "clínica" diz respeito à observação que se faz à cabeceira do doente. Observação certamente interessada porque coloca questões e sistemática porque formula hipóteses e tenta verificá-las conforme certas regras. Na posição deitada, o doente está involuntária e passivamente impotente e, no limite, desprendido de tudo que o rodeia, momentaneamente expulso da comunidade dos que estão erguidos (Canetti, 1960/1983). Deitado, regredido a sua mais tenra infância, ele se deixa observar pelo médico.

Essa observação do doente em sofrimento, que se apresenta em sua singularidade irredutível, coloca-se assim em oposição à observação anatomopatológica, hegemônica na constituição da medicina moderna, historicamente comprometida com o empírico e o descritivo ao privilegiar a visão - e cuja verificação das hipóteses (experimentais) é, digamos, estatística. A Anatomia Patológica, que “[permite] 'verificar' no cadáver a realidade das novas concepções médicas, desenvolveuse sob [...] princípios que forneceram a base da Nosologia e do vocabulário médico contemporâneo" (Clavreul, 1983 , p. 123). Dito de outra maneira, seu objeto constitutivo de estudo foi, a rigor, o cadáver, que permitiu informar de maneira objetiva, mediante as alterações anatômicas correspondentes, o processo e o desenvolvimento da doença. A eleição do cadáver como objeto de investigação é determinante dessa clínica experimental - que despreza o discurso do paciente. $\mathrm{O}$ paciente deve se calar sobre a doença que ele porta (ou sobre sua condição de doente), no entendimento de que promovida a cura sua "existência deixa de ser um problema" (Althusser, 1947, p. 14). Se nos últimos dois séculos a medicina moderna desvendou segredos jamais alcançados até então, é certo que a marca da patologia anatômica faz-se ainda hoje notar na relação que muitos médicos mantêm com seus pacientes.

Em uma palavra, o modelo médico é organicista, ou seja, considera que o patológico caracteriza-se pela doença do órgão físico. A existência ou não de lesão anatômica foi também para a psiquiatria do século XIX um fator de tal importância que, a partir dele, dois grandes grupos de doenças foram logo apartados. De um lado, as doenças que apresentavam uma sintomatologia regular e lesões orgânicas passíveis de identificação pela anatomia patológica; do outro, as neuroses, perturbações sem lesão e que não apresentavam a regularidade esperada.

Costuma-se aqui lembrar - merecidamente - o nome de Charcot e seus estudos sobre a histeria. Como se sabe, a histeria põe em xeque o método anatômico, pois os anatomistas jamais encontraram lesões que justificassem o aparecimento de sintomas histéricos. (Aliás, em que pese o grande esforço da psiquiatria oficial de inspiração crescentemente organicista nos últimos trinta anos, pode-se dizer que ainda hoje, mais de cem anos depois, não são identificáveis em sua maior parte, e pertencem ao domínio das hipóteses científicas não verificadas, lesões ou disfunções bioquímicas relativas até mesmo a certas psicoses graves.) Já em fins do século XIX, Charcot tenta demonstrar que, apesar da ausência de um referencial anatômico, a histeria apresentava uma sintomatologia bem definida, ou seja, ela obedecia a regras precisas. Isso lhe permite afastar o grande fantasma da psiquiatria naquele século, qual seja, a hipótese da simulação (Garcia-Roza, 1983).

Ao utilizar a hipnose como instrumento de pesquisa, e fisiologista "pouco inclinado a concepções psicológicas" (Freud, 1993, p. 18), Charcot abre de fato caminho para que Bernheim e a "École de Nancy" utilizem formas de intervenção clínica, ou terapêutica, nelas fundadas - em particular, a sugestão bipnótica, que o parisiense já utilizava em demonstrações públicas de suas teorias. Ora, como procedimento clínico, a hipnose inscreve-se no que chamaríamos, com Freud (1984), de tratamento psíquico (ou tratamento da alma). Atenção: este termo não significa tão somente o tratamento dos fenômenos patológicos da vida anímica, mas denota antes o tratamento que comeca pelo próprio psiquismo (seja de transtornos físicos ou psíquicos), através de procedimentos que atuam em primeiro lugar e de imediato sobre a alma humana.

Na verdade, lembra ainda Freud (1984), o tratamento psíquico no campo médico é historicamente o mais antigo e o único existente antes do advento da Anatomia Patológica, e quando a ars curandi pertencia aos sacerdotes. "O único médico do povo", já dissera Michelet (1962/ 1974) "foi, durante mil anos, a Feitiçaria" (p. 5) - como seria no mundo cristão o confessionário e o exorcismo. $\mathrm{O}$ exorcismo seria mesmo questionado em pleno Siècle des lumières pelo mesmerismo, supostamente científico mas à margem das concepções anátomo-patologicas já então dominantes - e precursor do hipnotismo no século XIX (Ellemberger, 1970/1994).

Neste movimento de recuperação e imposição do psicológico no interior mesmo da medicina moderna se inscreverá a psicologia clínica - na França, com Janet. Por sua vez, Freud, o inventor da psicanálise, também de formação médica e tendo exercido a profissão como neurologista da escola alemã, mantém o significante "clínica" para caracterizar procedimentos (clínicos) próprios e imanentes ao novo campo de conhecimento que se inaugura com o novo século - procedimentos 
que, afinal, desde o início não seriam (dos) médicos, e cada vez mais em escala mundial, deixam de ser (talvez nunca o tenham sido enquanto tal) dos psicólogos clínicos.

\section{A Psicologia Clínica Francesa}

Para Huber (1993) o termo "psicologia clínica" foi empregado pela primeira vez pelo psicólogo americano Witmer, quando, depois de se formar na Alemanha com Wundt, retorna à Universidade Pensilvânea e ali funda, em 1896, uma "psychological clinic". Também teria utilizado o termo "método clínico". Por sua vez, Prévost (1988) lembra que, entre 1897 e 1901, Hartemberg e Valentin (sucessores da "École de Nancy") publicam na França uma Revue de Psychologie Clinique et Thérapeutique na mesma época em que Janet (Salpêtrière) já empregava correntemente a expressão. Seja como for, Witmer e Janet, mais Ribot, Dumas e Kraepelin seriam autores cujos trabalhos, apoiados ao mesmo tempo sobre problemas psicológicos e psicopatológicos, distinguiram uma das duas correntes ou orientações com prolongamentos na psicologia clínica contemporânea. A outra seria representada por Charcot, Liébault, Bernheim e Freud (Ellemberger, 1970/1994, Huber, 1993).

Prévost (1988) supõe que, atento a tudo que aparece na França, Freud conheceu a Revue de Psychologie Clinique et Thérapeutique, talvez fosse mesmo a noção francesa que ele retoma na carta a Fliess de 30 de janeiro de 1899: “... percebo as relações com o conflito, com a vida, tudo isso que eu gostaria de chamar de psicologia clínica" (Freud, 1956, p. 244). Teria sido, contudo, a única vez que utilizou o termo, garantem Roudinesco e Plon (1997): "repousando sobre uma clínica, o método psicanalítico busca interpretar os sintomas através de uma escuta do inconsciente e não através da observação direta do paciente. Como tal, a noção não pode fazer parte do vocabulário freudiano" (p. 835) Para Prévost (1988), utilizando o termo, Freud "não o inventa, ele responde a uma idéia que vai dormir durante vinte e cinco anos" (p. 30).

$\mathrm{Na}$ França, a noção de psicologia clínica conhecerá aos poucos o ostracismo até ser recuperada por Lagache, que lhe imprime um vigor particular, sobretudo a partir de 1949, ao colocar em marcha seu programa de integração da psicanálise à psicologia. A partir dos anos 1960, a noção conhece um novo impulso "com o desen-

\footnotetext{
${ }^{3}$ Já para Gagey, Gori e Miollan (1983), a referência ao termo "psicologia clínica" corresponde ao momento em que, retirando a psicanálise do campo da psiquiatria, Freud estende sua démarche aos fatos normais do sonho e da vida cotidiana, com isso, justificando que a psicanálise deve fechar-se sobre si mesma.

Psicologia: Reflexão e Crítica, 2001, 14(3), pp. 609-616
}

volvimento da psicanálise de massa e a generalização dos estudos de psicologia" (Roudinesco \& Plon, 1997, p. 835).

Segundo Prévost \{1988), duas são as fontes da psicologia francesa: da primeira, nascida da cientificidade tradicional (Comte e Littré), resultou a psicologia experimental e o enquadramento do laboratório para servir ao rigor e ao domínio das variáveis. Da segunda, a "corrente dinâmica", e numa perspectiva continuísta, nasceu a antiga "psicologia das profundezas", a psicanálise (Áustria) e a psicologia clínica.

Por sua vez, a psicologia clínica francesa tem sua origem na confluência de duas grandes forças na época: a Filosofia e a Medicina. Para Prévost (1988) — que não menciona a célebre fala de Canguilhem, segundo a qual a psicologia seria uma filosofia sem rigor, uma ética sem exigência e uma medicina sem controle (Roudinesco, 1986) - a psicologia clínica seria rigorosa pelo lado da medicina e humanista pelo lado da filosofia. Ele considera ainda que, através de Lagache e Favez-Boutonier, e isso depois de 1949, a psicologia clínica percebeu, por detrás da totalidade, seu princípio, ou seja, a singularidade (princípio, aliás, que é o contrário da lei).

Os próprios biólogos teriam levado muitos anos até compreender a idéia de que a pessoa humana, o produto mais complexo da evolução, é irremediável e definitivamente singular. "Que essa singularidade, objeto último da clínica, faz apelo a uma filosofia do sujeito", sem dúvida, afirma então Prévost (1988), impossível — "eis aqui o que separa definitivamente a psicologia que toma isso como tarefa de uma positividade sempre pronta a separar essa totalidade, a buscar leis que unam as partes, a medir segundo unidades que não reenviam a nenhuma concretude definida” (p. 8). Não sendo esta em definitivo a posição da psicologia clínica, nem por isso ela deixaria de ter, na França, uma existência permeada de conflitos e disputas fundamentais: primeiro com a medicina, em seguida com a psicologia experimental e, enfim, depois de ter "encontrado sua salvação aproximando-se da psicanálise e oferecendo-lhe em troca um álibi universitário" (p. 5), com a própria psicanálise, sobretudo em sua vertente lacaniana.

A abordagem clínica, já dizia Lagache em 1949, devia ser aplicável ao indivíduo normal como condição para afastar-se de sua origem médica e psiquiátrica. Definindoa, em L'Unité de la Psychologie, como o estudo do homem concreto e completo face às situações - em sua situação, precisaria ainda Favez-Boutonier (1959) —, ele a via como a investigação sistemática e tão exaustiva quanto possível dos casos individuais. Usava também a noção de personnologie, que, designando a "ciência" oriunda da psicologia clínica, deveria permitir compreender as 
interações entre os elementos essenciais da personalidade e sua configuração de conjunto. (O sujeito-objeto da psicologia clínica lagachiana era o homem total em situação, o "em situação" da fenomenologia e sartriano).

Em busca desses elementos essenciais da personalidade, Lagache apoiava-se em testes, interrogatórios, prognósticos, orientação, coisas sem nenhuma relação "nem com uma clínica nem com uma teoria da personalidade" (Roudinesco, 1986, p. 232). Sem objeções, Anzieu (1979) explica que o exame desses casos individuais dizia respeito, antes de mais nada, à observação das reações verbais e afetivas do sujeito. As várias entrevistas aprofundadas visavam, primeiro, a reconstituição de sua anamnese, mas também testar seus níveis de tolerância, circunscrever seus pontos fracos, desencadear um processo associativo e eventualmente promover tomadas de consciência. Enfim, compreendia ainda a aplicação de testes projetivos.

$\mathrm{Na}$ psicologia clínica lagachiana, três postulados deveriam nortear a interpretação dos dados: dinâmico a investigação dos conflitos, no sentido freudiano; interrelacional - interação do indivíduo e do meio (Anzieu, 1979, p. 66), considerando a totalidade inacabada do ser segundo um modelo sartriano (Roudinesco, 1986, p. 232); e genético - apreensão da história de um sujeito em termos de evolução e resultado global. Também em 1949, pronuncia uma conferência em Estrasburgo ("Psicologia clínica e método clínico"): discriminando os modos de abordagens (ou "métodos") principais do estudo da conduta humana: a abordagem clínica, a abordagem psicanalítica e a abordagem experimental, sentencia: “O que especifica a psicologia clínica é o método clínico, isto é, a natureza das operações com as quais o psicólogo clínico aborda a conduta humana" (Lagache, 1979, p. 160). (A a firmativa, ponto-chave em nossa argumentação, merece ser destacada.)

Ao mesmo tempo janetiano (psicologia das condutas) e freudiano (inconsciente dinâmico), Lagache queria mostrar que "a psicanálise era uma psicologia das condutas e que a conduta do psicanalista consistia no essencial em fazer, nas condições muito particulares de 'laboratório', a síntese interpretativa dos fragmentos de conduta fornecidas pelo paciente" (Roudinesco, 1986, pp. 73-74). No Dicionário, Roudinesco e Plon (1997) definem a psicologia clínica como prática terapêutica fundada na entrevista direta e no exame de caso a partir da observação das condutas individuais (science du sens intime). A definição assenta-se no ideário lagachiano: por psicologia clínica (francesa, sem dúvida) deve-se entender o estudo dos casos individuais, cujo método repousa sobre os três postulados referidos acima: a dinâmica, a totalidade, a gênese. Desses três postulados derivam os fins práticos: o psicólogo clínico cura doentes, educa crianças, aconselha adultos (Prévost, 1988) e, acrescenta Roudinesco (1986), reclassifica inadaptados.

O psicanalista seria "um psicólogo clínico que se limita a curar e a utilizar uma só técnica (a investigação psicanalítica), entre cinco ou oito, mas utilizando-a a fundo" (Prévost, 1988, p. 74), e a psicanálise uma ultra-técnica, por visar a apenas um dos quatro alvos da psicologia clínica, quais sejam: o diagnóstico, o conselho, o tratamento, a educação. De sua parte, em função da diversidade de lugares onde trabalha o psicólogo clínico e da variedade de sua prestação de serviços, a psicologia clínica lagachiana compreende um campo muito mais vasto de atuação - logo, heterogêneo e amplo no tocante às suas fontes de informação. Fundamentando-se teoricamente na psicanálise e apoiando-se nela como modelo operatório, a psicologia clínica nem por isso deveria ser incompatível com as outras orientações teóricas e metodológicas da psicologia. Sabe-se que, desde 1949, Lagache considerava ultrapassado o conflito entre psicologia experimental e psicologia clínica, e estimava que a unidade da Psicologia resultaria do apoio mútuo que se emprestam o método experimental e o método clínico. Sem negar o conflito, parecia-lhe fecundo o reconhecimento pelos clínicos dessa tensão dinâmica no interior mesmo de sua própria disciplina (Anzieu, 1979).

O fundador de fato da psicologia clínica francesa talvez estivesse mesmo equivocado, pelo menos do ponto de vista da psicanálise: enquanto Lacan postulava a irredutibilidade de toda psicologia à primazia da determinação inconsciente - "a psicologia não poderia ser senão o objeto de uma ilusão imaginária, da qual a psicanálise explica as competências e os impasses [enjeux]" (Gagey, Gory \& Miolan, 1983, p. 309) —, ele apostava, ao contrário, na sua integração: "contra o dinamismo ao qual ele deve em parte sua formação, repensa a unidade da psicologia sob a categoria de uma filosofia da consciência..." (Roudinesco, 1986, p. 234). Em 1953, favorece o relançamento do experimentalismo, tornandose diretor do Instituto de Psicologia da Universidade de Paris. As duas correntes, porém, não sustentariam o projeto unitário: para a filosofia da consciência, a psicologia clínica estava muito próxima da psicanálise e, para os experimentalistas, ela não era "suficientemente 'científica' aos olhos de um modelo neo-fisiológico ou neobiologista" (Roudinesco, 1986, p. 234). Psicólogo no meio analítico, psicanalista entre os psicólogos, teria sido assim que Lagache se viu derrotado em sua "batalha unitária". 


\section{Psicologia Clínica e Método Clínico}

Em 1979, segundo Anzieu, constituindo os psicólogos clínicos maioria na França, eram psicanalistas 2/3 dos professores dessa habilitação. Por sua vez, em 1988, Prévost afirma que permanecia difícil a questão das relações entre psicologia clínica e psicanálise, e polêmicas ou pessoais as soluções propostas (que de resto ele não enumera). Contudo, frisava, não se tratava de uma problemática vã.

Ora, em 1993, Huber não hesita em exprimir o desejo de que "a psicologia clínica francesa liberte-se de sua fixação na psicanálise, abandone suas querelas locais e retome o diálogo com a comunidade científica internacional” (p. 11). Para resolver os impasses da psicologia clínica francesa, propõe direcioná-la para o caminho que, na sua avaliação, tem sido a tendência mundial desde os anos 1960. Define-a como o ramo da psicologia científica — segundo ele, o mais forte — "que tem por objeto os problemas e os distúrbios psíquicos assim como a componente psíquica dos distúrbios somáticos ou, se preferir, o estudo do que constitui problema nas condutas normais e patológicas e da intervenção nessas condutas". Incluindo portanto o homem psicopatológico ${ }^{4}$, a psicologia clínica não está limitada "aos pontos de vista de uma escola [e] desenvolve-se num contexto cada vez mais interdisciplinar". Esta interdisciplinaridade, continua ele, "não se limita à fenomenologia, à psicanálise e à linguística, mas compreende também a economia, o direito e as ciências ditas da vida e da saúde" (Huber, 1993, p. XIV).

$\mathrm{Na}$ mesma perspectiva, encontra-se Schraml (1973), cujo livro, Abriss der Klinischen Psychologie, publicado originalmente em 1968, está devidamente listado na bibliografia de Huber em seus diversos manuais. Para Schraml, que entende por psicologia clínica "a aplicação no domínio clínico dos resultados e métodos de todas as disciplinas psicológicas fundamentais específicas...", o termo método clínico "recobre todo procedimento de

\footnotetext{
4 De acordo com Huber (1993), a história antiga e recente da psicologia clínica mostra uma enorme variedade de pontos de vista e definições, dependendo da posição teórica dos autores e, às vezes, "de sua preocupação em evitar conflitos territoriais com a medicina" (p. 15). Para alguns, como Hellpach (1946), seria objeto da psicologia os comportamentos que acompanham as doenças corporais e não "as doenças primariamente psíquicas" ou "desvios da norma" (psicoses, neuroses, psicopatias). Outros, como Stern (1954) vão contestar justamente essa exclusão dos transtornos psiquiátricos, mas consideram a psicoterapia uma atividade médica. Outros ainda, como Schraml (1973), a psicoterapia é integrada à psicologia clínica. Enfim, Lagache (1949) e Favez-Boutonier (1959) realizam uma "discussão sutil do objeto, dos métodos e aplicações, que eles situam [...] em relação à psicanálise" (p. 15).

observação direta e minuciosa na entrevista ou nas situações experimentais definidas (situações de teste)". Porém, lembrando que foi antes de tudo nas ciências da natureza que surgiu o hábito de definir uma disciplina segundo o método utilizado, onde ele é corrente apenas na pesquisa fundamental, o psicólogo clínico alemão acredita que "é da natureza das ciências aplicadas ter que utilizar diferentes métodos e, por isso, é racional definilas somente por seu campo de aplicação" (p. 10).

Ora, Lacan (1966) entende que a psicanálise pode ser aplicada no sentido próprio apenas como tratamento, ou seja, aplicada a um sujeito que fala e que ouve. Para Roudinesco e Plon (1997), com isso ele quer indicar que "qualquer outra forma de aplicação se faria apenas no sentido figurado, isto é, imaginário, fundada sobre o analógico e, como tal, sem eficácia" (p. 828). Deste ponto de vista, crítico, talvez se tenha originado o tom freqüentemente pejorativo com que hoje em dia se enuncia a noção de "psicanálise aplicada". Interessa-nos aqui de todo modo evidenciar que, não sendo apenas discursividade, a psicanálise "tem a ambição não só de descrever ou de inventar alguma coisa no plano ideal, mas também a pretensão de intervir nesse real e de modificar alguma coisa dele. Isso se dá na experiência analítica” (Mezan, 1994, pp. 58-59), logo, pela via da transferência. Ciência aplicada, sim, mas de uma maneira especial e particular: primeiro, sua prática clínica ou terapêutica também é em si mesma e ao mesmo tempo uma forma de investigação. Segundo, se levamos em conta o hábito de definir uma disciplina segundo o método utilizado (como vimos acima com Schraml), a psicanálise, que se define pelo seu método (o método psicanalítico), estaria mais próxima das Naturwissenschaften - o que muito agradaria Freud -, e de uma pesquisa fundamental.

Huber (1993), em sua concepção de psicologia clínica, não se refere ao método clínico no singular. Ao discorrer sobre método em psicologia clínica, o psicólogo belga distingue os métodos de pesquisa, que permitem constituir o corpo de saber da disciplina, daqueles que viabilizam a aplicação desse saber no nível do diagnóstico e da intervenção - evidenciando assim que a intervenção clínica em psicologia, como em toda ciência genuinamente aplicada, faz-se em dois tempos distintos.

No primeiro caso, como métodos de pesquisa em psicologia clínica, ele cita principalmente: 1) o estudo de caso, 2) o estudo correlacional, 3) o estudo normativo, 4) a experimentação, 5) as estatísticas e os planos experimentais.

No nível do diagnóstico e da avaliação clínica, ele cita 1) a entrevista diagnóstica, 2) os testes mentais, 3) a observação 
e a análise do comportamento, e a análise psicodinâmica; 4) os métodos biológicos. (Tudo descrito, ele discute em seguida as condições de validação). Enfim, no nível da intervenção, deduz-se que ele leva em conta os métodos que, a seu ver, seriam próprios dos quatro campos maiores assim discriminados: 1) a neuropsicologia clínica; 2) a psicologia da saúde; 3) o aconselhamento psicológico, a intervenção de crise e a psicoterapia (sendo as cinco orientações teóricas maiores: as terapias psicanalíticas, as terapias comportamentais, as terapias humanistas, as terapias familiares e sistêmicas, as terapias biopsicológicas); enfim, 4) a psicologia comunitária.

Não deve ser desprezado o fato de Huber (1993) finalizar a descrição das orientações teóricas maiores em psicoterapia com um subitem que sublinha a "crise dos sistemas e o declínio do pensamento centrado nas escolas" (p. 273). Em conseqüência dessa crise, ele detecta uma maior abertura às mais diversas técnicas terapêuticas e, seu corolário, a idéia de desenvolver combinações específicas de tratamentos para certos problemas e distúrbios. E no âmbito mesmo de formação, estaria ocorrendo um alargamento do repertório dos métodos e técnicas - segundo ele, uma exigência já naquele momento em vigor na Holanda e na antiga RFA. Na impossibilidade de seguir formações em diversas escolas - "é preciso guardar o ponto de vista e um enraizamento" (p. 274) —, tratar-se-ia de conhecer e ser competente nos diferentes métodos terapêuticos centrados nos problemas do paciente (o que nos parece, no mínimo, uma impossibilidade e uma impropriedade).

Mas aqui reconhecemos de imediato o chamado "ecletismo" em psicoterapia, ainda muito em voga, sobretudo nos Estados Unidos. Nem Lagache, que fracassou, chegaria tão longe em sua pretensão de promover a unidade da psicologia. No fundo, a concepção "huberiana" de psicologia clínica radicaliza aquela de Lagache, com a diferença de que a psicanálise, em vez de servir privilegiadamente de apoio, como fundamentação teórica e modelo operatório, é aqui antes denunciada por sua suposta influência maciça (e a seu ver nefasta, no que concerne a psicologia clínica francesa).

Por sua vez, e não por acaso, Schraml (1973) acredita que, além de não ser vantajoso, um mal-entendido poderia então surgir se o método clínico fosse tomado como critério de uma psicologia clínica - justamente o que tentaram fazer Lagache, na França, e, acrescenta Schraml (1973), Piaget, na Suiça. Por um lado, esclarece, porque se trata de um termo já anexado pela medicina; por outro, porque a psicanálise e "algumas ciências aparentadas" (p. 9) utilizam-no igualmente.

\section{A Título de Conclusão}

Para Freud (1912/1976), ainda que o termo "psicanálise" seja definido em três níveis ${ }^{5}$, a palavra método vem sempre no singular, Por exemplo, referindo-se ao "método catártico" do qual deriva o método psicanalítico: "Quando eu comecei [...] a praticar sobre meus próprios doentes o método de investigação e de tratamento de Breuer..." (Freud, 1993, p. 12). Ou então, mais explicitamente: "Uma das reivindicações da psicanálise em seu favor é, indubitavelmente, o fato de que, em sua execução, pesquisa e tratamento coincidem..." (Freud, 1912/1976, p. 152). À sua maneira, reconhece Stengers (1990), historiadora e filósofa das ciências: "Na psicanálise, tal como Freud a inventa, a purificação e a elucidação, isto é, o trabalho de pesquisa e de cura [sic], são estritamente contemporâneos. [...] Freud cria um novo tipo de ciência experimental onde a purificação pela transferência [...] não é separável da operação que ela condiciona" (p. 123).

À luz de tudo que foi exposto até agora, pode-se depreender o seguinte: ao negar a existência de um método clínico em psicologia o que se pretende é, sobretudo, o divórcio metodológico entre psicologia clínica e psicanálise, e ao mesmo tempo conservar o direito de uma utilizar a outra enquanto mero procedimento técnico - logo, destituída de pressupostos ético-epistemológicos muito precisos. Ora, sendo assim, esse divórcio conviria também à psicanálise: em termos analíticos e para fins analíticos, o saber clínico refere-se àquele obtido unicamente pela via da transferência, na escuta do paciente em sua condição de sujeito do inconsciente e portador de uma realidade psíquica singular jamais levada em conta, no limite, em outras situações de investigação.

Vale ainda supor que a psicologia clínica corre o risco de se limitar à mera confirmação de dados aprioristicamente conhecidos, quando, privilegiando a separação artificial entre investigação e intervenção, evita o confronto direto com o real do acontecimento clínico, impedindo dessa forma o surgimento do novo - o

\footnotetext{
5 "Disciplina fundada por Freud e na qual, com ele, podemos distinguir três níveis: a) um método de investigação que consiste essencialmente na evidenciação do significado inconsciente das palavras, das ações, das produções imaginárias (sonhos, fantasmas, delírios) de um indivíduo [...]. b) Um método psicoterápico baseado nesta investigação e especificado pela interpretação controlada da resistência, da transferência e do desejo [...]. c) Um conjunto de teorias psicológicas e psicopatológicas em que são sistematizados os dados introduzidos pelo método psicanalítico de investigação e de tratamento" (Laplanche \& Pontalis, 1973, pp. 350-351).
} 
"frescor da vida" que a situação transferencial restitui (Freud, 1926/1992, p. 274). Em suma, uma opção que não se coaduna com as características históricas, constitutivas e fundamentais da clínica: a incerteza, o tateamento, a sugestão, a resistência e a repetição, a suspeita, a dúvida, a diferença, enfim, o singular.

Cabe assim perguntar se, fascinada por procedimentos experimentais (tal como ocorre com os médicos, com relativo sucesso, em suas confirmações ambulatoriais), essa psicologia clínica ampliada não estaria, no limite, abandonando uma abordagem do sujeito que leva em conta sua singularidade radical. Submetendo-se ao cânone científico (sempre vigente) da generalização a partir de amostragens, ela adia para um futuro incerto a consideração das condições de possibilidade e os princípios próprios de um tal saber (sobre o singular), mais conforme às ciências da vida, cuja marca - como na psicanálise freudiana - é o detalhe, e que trabalha de maneira muito específica e particular a noção de exemplo. Como quer Assoun (1984), que se inspira em Freud (1909/1974), o exemplo psicanalítico, sendo a coisa mesma, é quem faz surgir a lei6 .

Desprezando assim, em algum nível, essas duas dimensões - singularidade do sujeito e contemporaneidade entre pesquisa e tratamento - a noção de método clínico perverte-se e, de fato, perde toda sua razão de ser enquanto critério para especificar a psicologia clínica (digamos, oficial e internacional). Na clínica psicanalítica, a primeira dessas dimensões é sobretudo uma exigência ética, e a segunda, um pressuposto epistemológico: caso se mantenha o termo, a noção de método clínico pertence-lhe por direito. E então, sem mal-entendidos, será possível considerar (intramuros) que a noção de método clínico subsume-se (como variante, ainda que fundadora e constitutiva) à noção de método psicanalítico. A este caberia ainda "provar que [as] forças, que segundo a psicanálise animam toda e qualquer produção mental, individual ou coletiva, podem ser detectadas não apenas na situação clínica, mas ainda nas produções secundarizadas" (Mezan, 1994, pp. 67-68). Aliás, como foi o desejo do próprio Freud (análise leiga) e exercício efetivo, recorrente e fecundo ao longo de sua obra.

6 “Toda investigação psicanalítica é do tipo qualitativo, ou seja, trabalha em profundidade com casos específicos. "É o mergulho na sua singularidade que permite extrair dele tanto o que lhe pertence com exclusividade quanto o que compartilha com outros do mesmo tipo: por isso o caso ganha um valor que se pode chamar de exemplar" (Mezan, 1999, p. 21).

\section{Referências}

Aguiar, F. (1990). Da sugestionabilidade à transferência. Elementos para um estudo da formação do conceito de transferência em Freud. Dissertação de Mestrado não-publicada, Curso de Pós-Graduação em Filosofia, Universidade Federal de Minas Gerais, Belo Horizonte, MG.

Aguiar, F. (1991). Da sugestionabilidade à transferência: Itinerário de Freud. Kriterion, XXXII, 83-84, 1-24.

Aguiar, F. (2000). Psicanálise e Universidade: das relações entre a Psicologia Clínica e a Psicanálise na França. Estudos de Psicologia, 5(1), 215-241.

Althusser, L. (1947). Situation bistorique de l'Église. Jeunesse de l'Église. Paris: Petit Clamart.

Anzieu, D. (1979). La psychanalyse au service de la psychologie. Nouvelle Revue de Psychanalyse, 20, 59-75.

Assoun, P. -L. (1981). Introduction à l'épistémologie freudienne. Paris: Payot.

Assoun, P. -L. (1984). L'entendement freudien - Logos et Anankè. Paris: Gallimard.

Beauchesne, H. (1986). Histoire de la psychopatologie. Paris: PUF.

Canguilhem, G. (1968). Études d'histoire et de philosophie des sciences. Paris: Vrin.

Canetti, E. (1983). Massa e poder. São Paulo: Melhoramentos. (Original publicado em 1960)

Clavreul, J. (1983). A ordem médica. Poder e impotência do discurso médico. São Paulo: Brasiliense. (Original publicado em 1978)

Ellemberger, H. F. (1994). Histoire de la découverte de l'inconscient. Paris: Fayard. (Original publicado em 1970)

Favez-Boutonier, J. (1959). La psychologie clinique. Objet, méthode, problèmes (I-II). Paris: CDU.

Freud, S. (1956). La naissance de la psychanalyse. Paris: PUF.

Freud, S. (1974). L'homme aux rats. Journal d'une analyse. Paris: PUF. (Original publicado em 1909)

Freud, S. (1976). Recomendações aos médicos que exercem a psicanálise. Em S. Freud (Org.), Edição standard da obras completas de Sigmund Frend (Vol. XII, pp. 147- 159). Rio de Janeiro: Imago. (Original publicado em 1912)

Freud, S. (1984). Traitement psychique (Traitement d'âme). Em S. Freud (Org.), Résultats, idées, problèmes (Vol. I, pp. 1-24). Paris: PUF. (Original publicado em 1905).

Freud, S. (1992). Inhibition, symptôme et angoisse. Em S. Freud (Org.), Euvres complètes (Vol. XVII, pp. 203-286). Paris: PUF. (Original publicado em 1926).

Freud, S. (1993). De la psychanalyse. Em S. Freud (Org.), Euvres complètes (Vol. X, pp. 1-55). Paris: PUF. (Original publicado em 1909)

Gagey, J., Gory, R. \& Miolan, Cl. (1983). Psychologie clinique et psychanalyse: D’une inquiétante familiarité. Psychanalyse à l'Université, 30, 305-314.

Garcia-Roza, L. A. (1983). Freud e o inconsciente. Rio de Janeiro: Zahar.

Hellpach, W. (1946). Klinische Psychologie. Stuttgart: Thieme.

Huber, W. (1987). La psychologie clinique aujourd'bui. Bruxelas: Mardaga.

Huber, W. (1993). L'bomme psychopathologique et la psychologie clinique. Paris: PUF.

Huber, W. (1993/2). Les psychothérapies. Quelle thérapie pour quel patient? Paris: Nathan.

Lacan, J. (1966). Jeunesse de Gide ou la lettre et le désir. Écrits, 739-764. Paris: Seuil.

Lagache, D. (1949). L'unité de la psychologie. Psychologie expérimentale et psychologie clinique. Paris: PUF.

Lagache, D. (1979). Psychologie clinique et méthode clinique. La psychologie et le criminel, II, 159-294. Paris: PUF.

Laplanche, J. \& Pontalis, J. -B. (1973). Vocabulaire de la psychanalyse. Paris: PUF.

Mezan, R. (1994). Pesquisa teórica em psicanálise. Psicanálise e Universidade, 2, 51-75.

Michelet, J. (1974). Sobre as feiticeiras. Lisboa: Afrodite. (Original publicado em 1862)

Prévost, C. -M. (1969). À propos des origines de la psychologie clinique. Bulletin de Psychologie, 23, 119-124.

Prévost, C. -M. (1973). Janet, Freud et la psychologie clinique. Paris: Payot.

Prévost, C. -M. (1988). La psychologie clinique. Paris: PUF. 
Reuchlin, M. (1961). Histoire de la psychologie. Paris: PUF.

Roudinesco, E. (1986). La bataille de cent ans. Histoire de la psychanalyse en France II. Paris: Seuil.

Roudinesco, E. \& Plon, M. (1997). Dictionnaire de la psychanalyse. Paris: Fayard.

Schraml, W. J. (1973). Précis de psychologie clinique. Paris: PUF.

Stengers, I. (1990). Quem tem medo da ciência? Ciência e poderes. São Paulo: Siciliano.
Stern, E (1954). Handbuch der Klinischen Psychologie. Die Tests in der Klinischen Psychologie (Vol.1). Berlim: Springer.

Sobre o autor

Fernando Aguiar é Graduado em Psicologia, Mestre e Doutor em Filosofia, respectivamente, pela Universidade Federal de Minas Gerais e pela Universidade Católica de Louvain (Bélgica). Atualmente é professor adjunto do Departamento de Psicologia da Universidade Federal de Santa Catarina, leciona disciplinas (Graduação e Pós-Graduação) na área de Psicanálise. 